\title{
Comparison of Bus Driving Control Based on Working Shift Hour and Impact on Bus Fuel Consumption
}

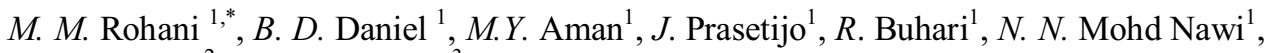 \\ N. S. A. Sukor ${ }^{2}$, and S. A. Hasan ${ }^{3}$ \\ ${ }^{1}$ Faculty of Civil and Environmental Engineering, Universiti Tun Hussein Onn Malaysia, 86400 Batu \\ Pahat, Johor, Malaysia \\ ${ }^{2}$ School of Civil Engineering, Universiti Sains Malaysia \\ ${ }^{3}$ Faculty of Civil Engineering, Universiti Teknologi Malaysia
}

\begin{abstract}
This study is aimed to investigate and compare how the work schedule of bus drivers in urban areas can have impact on bus drivers' control on speed and acceleration. This study also assesses the influence of bus driving behavior on fuel consumption. The work schedule assessed in this research is morning shift (6.00 am to $3.00 \mathrm{pm})$, afternoon shift (3.00 $\mathrm{pm}$ to midnight) and direct shift (6.00 am to midnight). The result from this study indicated that for all driving shifts, drivers spent more than $70 \%$ of their driving time for accelerating and braking. Drivers were also significantly driving faster and applying sharper acceleration when accelerating and braking during morning shift. The variation of bus driving behavior between different working shift hours were found to influence bus fuel consumption significantly.
\end{abstract}

\section{Introduction}

There are some evidence that working shift hour can directly influence driver behavior. This can be seen in Rospa [1] study on driver fatigue and road accidents. Researcher suggested that drivers who are working on early morning (12 am) and in the afternoon have higher accidents risks as drivers are prone to fell asleep. Horne and Reyney [2] supported the statement in their research about sleepy driver. They suggested that driving for a long period is boring and will cause sleepiness. Besides that, the researchers suggested that the driver will be 50 times sleepier and have 3 times more risk to accident at 2 am compared to $10 \mathrm{am}$. Results from 102 operators who were involved as a sample in Howarth [3] study demonstrated that there are different sleep length between drivers who work split shift (two periods of work within one day) and straight shift (non-split). The study about investigation of sleep length and fatigue of transit bus operators while working with different work schedules found split shift drivers sleep less on working days compared to straight shift drivers. From that, Howart suggested drivers who work on split shift are more exposed to mental fatigue compared to drivers who work on straight shift.

* Corresponding author: munzilah@uthm.edu.my 
The study carried out towards transit bus driver in Florida also found that drivers who work in split shift tend to get fatigue compared to straight shift due to inadequate rest [4]. Researchers performed the analysis using Fatigue Audit Interdynamics (FAID) to relate between fatigue and accident (divided into red, yellow, and green) found the result is $56.48 \%$ (in red) which shows fatigue is related to accidents. Apart from that, the increasing higher risk of accidents at peak hours (at night) multiplied 10 times from daytime. Therefore, working shift influences the driver's performance and safety. A previous study has shown that fatigue, increases as working time increases, with associated increase in accidents. Past research about the factors of fatigue and bus accident suggested that working schedule is a cause of accidents as irregular working hours led to fatigue and causing accidents [5]. Besides that, unsuitable working schedule also caused lack of rest or sleep to the bus drivers and will affect their driving performance.

Since it is known that working shift hour can have impact on driver behavior, it is no doubt that driving behavior is the main factor impacting bus fuel consumption. For example, study carried out in Southampton by Rohani [6] on bus driver issues and fuel consumption suggested that fuel consumption is sensitive towards acceleration change. The change of driving behavior from aggressive to normal and from normal to economic provides the fuel saving of $20 \%$ to $40 \%$. However, the fuel consumption increases to $67 \%$ when the driver accelerates from rest. According to Mierlo e al. [7], the changing of driving behavior from aggressive to pro-aggressive can reduce the fuel consumption of $5 \%$ to $25 \%$ while Vlieger et al. [8] suggested that aggressive driving behavior increases the fuel consumption until $40 \%$ but it also depends on road conditions and vehicle technology.

Another study that showed the impact of driving behavior on fuel consumption was carried out in Belgium [9]. Researchers reported that the average of fuel consumption before and after attending driving course have shown a reduction at about $5.8 \%$. The difference in fuel usage was also determined by the change of driving behavior based on economic driving tips such as gear changing after approaching $2000 \mathrm{rpm}$, using steady speed and reducing gear change especially during long journeys.

\section{Research approach}

The four research buses used in this study were lower floor single decker Scania. It has a Euro 3 engine with six automatic gear transmissions. The bus weight with and without load are $11000 \mathrm{~kg}$ and $18000 \mathrm{~kg}$ respectively. Global Positioning System (GPS) (GLOBALSAT DG-200 model) device was used to collect real speed profile, bus position, date and time from research buses (Fig. 1). The devices were mobile based device and powered by an internal battery. Data were stored in its internal data logger at $1 \mathrm{~Hz}$, allowing up to 24 hours of continuous data collection. The GPS was placed on board on each research bus without the knowledge of the drivers so that the drivers will drive the bus based on their actual behaviour.

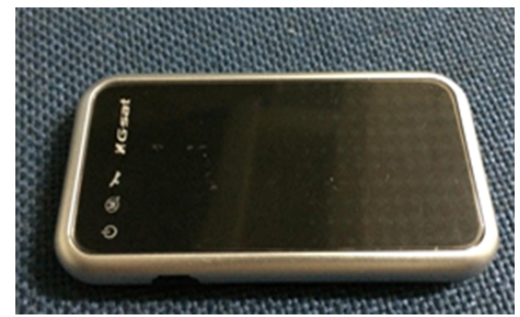

Fig. 1. Global Positioning System (GPS) device used in this study 
Eleven bus drivers from private bus company participated in this study and were asked to drive the bus based on their working shifts hours. Three different working shifts implemented by the bus company are morning shift, afternoon shift and full day shift. The duration hours for these working shifts are between $6.00 \mathrm{am}$ to $3.00 \mathrm{pm}$ ( 9 hours), $3.00 \mathrm{pm}$ to $12.00 \mathrm{am}$ (9 hours) and $6.00 \mathrm{am}$ to $12.00 \mathrm{am}$ (18 hours) respectively. In the middle of the drivers' working period, they were given break time to ensure that they have sufficient rest so that they are to be able to drive the bus safely.

Route selected for this research connecting center of Putrajaya and Cyberjaya. During the period of data collection, the buses were driven continuously based on bus trip schedule for both directions from Putrajaya to Cyberjaya and from Cyberjaya to Putrajaya by drivers. Each bus driving trip (for both directions) took between 30 to 45 minutes. As presented in Table 1 total of 549 driving profile were observed within 2 weeks of data collection.

Table 1. Number of driving profile observed based on working shift period

\begin{tabular}{|c|c|c|}
\hline \multirow{2}{*}{ Bus Route } & Working Shift period & $\begin{array}{c}\text { Number of driving profile } \\
\text { observed }\end{array}$ \\
\hline \multirow{2}{*}{$\begin{array}{c}\text { Putrajaya to } \\
\text { Cyberjaya }\end{array}$} & Morning & 113 \\
\cline { 2 - 3 } & Afternoon & 81 \\
\cline { 2 - 3 } & Full day & 71 \\
\hline \multirow{2}{*}{$\begin{array}{c}\text { Cyberjaya to } \\
\text { Putrajaya }\end{array}$} & Morning & 120 \\
\cline { 2 - 3 } & Afternoon & 74 \\
\cline { 2 - 3 } & Full day & 90 \\
\hline \multicolumn{2}{|c}{} \\
\hline
\end{tabular}

\section{Research data}

Data were downloaded from GPS datalogger during the end of the bus daily schedule. Since the GPS recorded the data continuously and unable to split the data according to research needs, this process was conducted manually using Microsoft Excel software and Google Maps. In addition, the GPS recorded the time based on Coordinated Universal Time (UTC). Therefore, the research data need to be adjusted based on Malaysia time. It should be noted that, the hour differences between UTC time and Malaysia time is 8 hours. Further to the data processing, the acceleration data used in the analysis were calculated from the speed change recorded by GPS devices.

An additional software: SIDRA TRIP was used in this study to estimate bus fuel consumption based on driving profile and the bus' specific parameters such as engine size, bus load, etc. To ensure the fuel estimation is correct for further analysis, the estimated fuel data were compared with daily fuel filled recorded in log book. As the result from comparison test have shown that SIDRA TRIP fuel estimation was not significantly different from fuel used recorded in the log book, the estimated fuel consumption were used for further analysis.

\section{Analysis and results}

\subsection{Research data}

In present study, the driving styles of the bus driver were experimentally monitored to investigate the variation of the speed and acceleration control. Further to the investigation, fuel consumption impact from driving styles has been determined. It is based on real time 
measurement from four research buses driven by eleven bus drivers. Dynamic variables of speed, acceleration and estimated fuel consumption have been analysed. Each data was categorized based on driving phases of idling, cruising, accelerating and braking. It should be noted that the term 'accelerating' and 'braking' used in this study refers to any data with positive and negative acceleration respectively. The overall proportion of driving phases derived from the entire data are as presented in Fig. 2. It shows that more than $70 \%$ of bus driving activity in city environment was for accelerating and braking. These driving phases are the major cause of higher fuel consumption (Fig. 3).

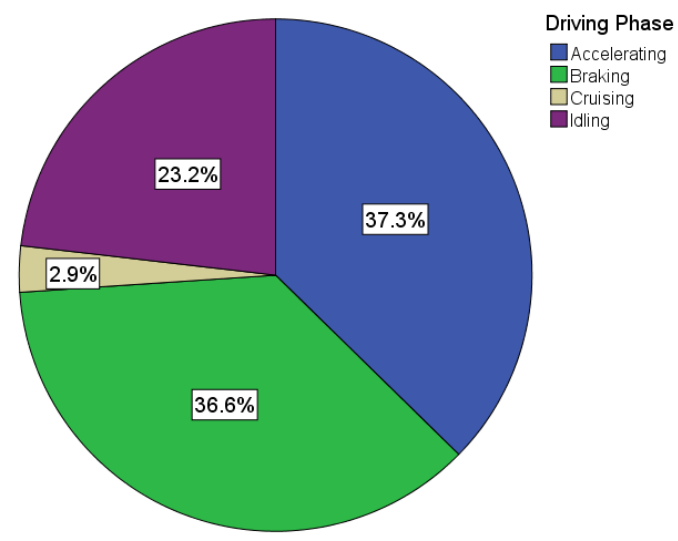

Fig. 2. Proportion of driving phase in the research data

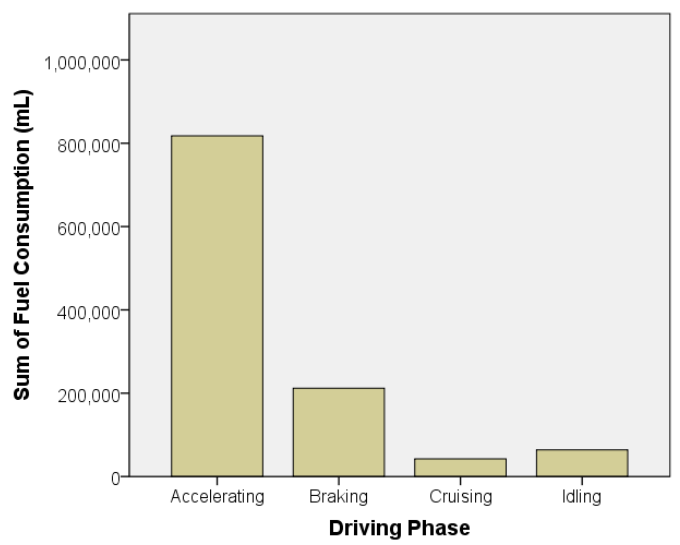

Fig. 3. Sum of fuel consumption according to different driving phase calculated from research data

In Fig. 4 to Fig. 6, the distribution of speed, acceleration and fuel consumption measures are shown. The observed speed peaked at lower speed range of $0-2 \mathrm{~km} / \mathrm{h}$ is normal for bus driving in city environment due to stop and go activities; as the drivers are require to stop at signalized intersection for red light, or due to traffic interruption within the road segment. Furthermore, since the bus serves passengers in town areas, passenger boarding and alighting activities at dedicated bus stop not only influnce the speed but also the acceleration data's distribution. As presented in the graph, the acceleration calculated from the speed change, range between -3.94 to $2.69 \mathrm{~m} / \mathrm{s}^{2}$. The peak acceleration was observed at lower acceleration ranged at $0-0.2 \mathrm{~m} / \mathrm{s}^{2}$. The distribution of speed and 
acceleration captured from the data are also found to influence $30 \%$ and $63 \%$ of bus fuel consumption respectively.

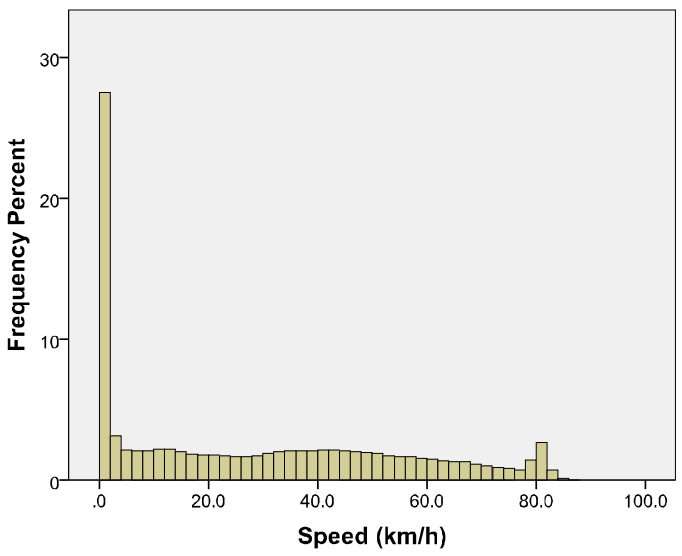

Fig. 4. Distribution of bus speed

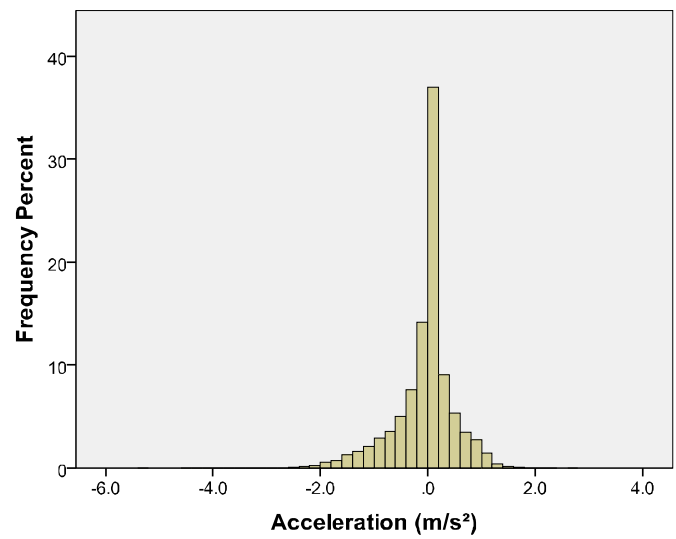

Fig. 5. Distribution of bus acceleration

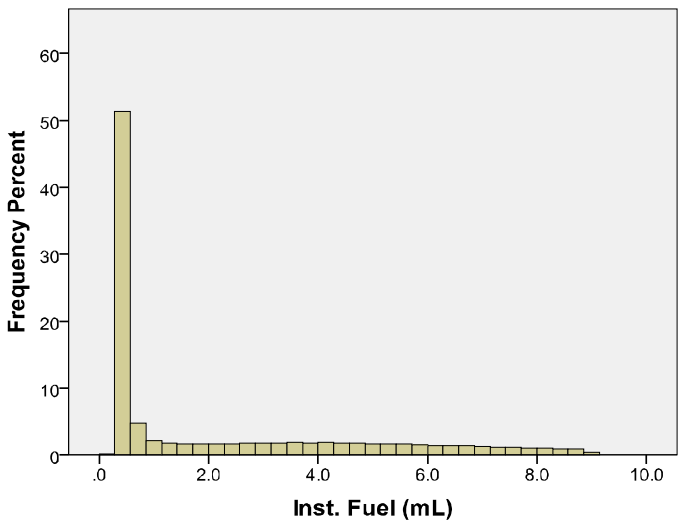

Fig. 6. Distribution of bus fuel consumption 


\subsection{Comparison of acceleration and deceleration control of bus drivers based on working hour shift}

One of the aims of this study is to compare the variation of bus speed and acceleration control during the three different working hour shifts as mentioned in the research approach. Fig. 7 presents the proportion of driving phases spent by drivers who work at different working shift hour. The figure exhibits that the driving phase proportion between the drivers who work at different working hour shift are not significantly different. It was shown that, in the city environment, bus drivers were dealing with majority of accelerating and braking (more than 70\%) control. Beside unable to maintain the constant speed, the bus drivers were also found to spend more than $20 \%$ of their journey time for idling. Traffic and road geometric factors are generally seen as strong factors that influence how the drivers control their driving.

To further investigate, the analysis was conducted to examine whether the drivers control the speed and acceleration differently at different working shift hour. The overall result from correlation test indicated that, speed, and acceleration control and driving hour shift have low correlation to each other $(\mathrm{R} 2<0.1)$. However, the mean and maximum speed and acceleration reached by the drivers as presented in Table 3 suggested that mean acceleration rate when accelerating is higher among drivers who drove in direct shift $(0.339$ $\mathrm{ms}^{-2}$ ). As for braking behavior, the overall data showed that, mean of deceleration rate when drivers braking was higher in morning shift $\left(-0.550 \mathrm{~ms}^{-2}\right)$.

The significant difference of bus driving control is not only shown when drivers were accelerating and braking, but was also captured in bus speed control (as shown in Table 2). As presented in Table 3, mean speed is higher during morning shift driving $(29.48 \mathrm{~km} / \mathrm{h})$ followed with direct shift $(27.969 \mathrm{~km} / \mathrm{h})$. Specifically, drivers who work for direct shift were also found to apply $4 \%$ (accelerating) and $8 \%$ (braking) higher acceleration rate during morning shift.

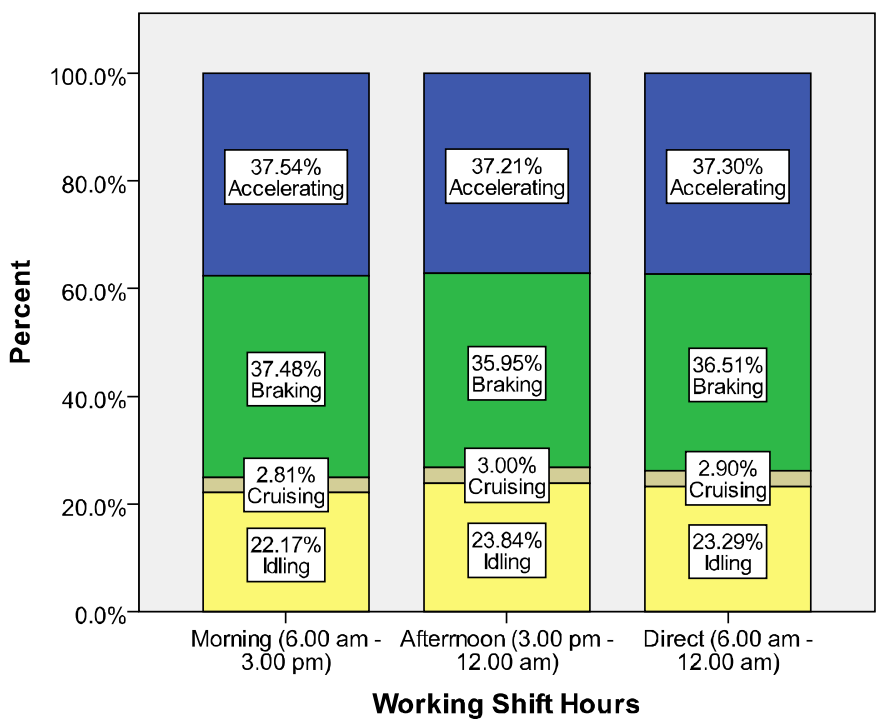

Fig. 7. Proportion of driving phases spent indifferent working shift period 
Table 2. Comparison test for acceleration and speed control between different working shift hour

\begin{tabular}{|c|c|c|c|c|c|c|}
\hline & & $\begin{array}{c}\text { Sum of } \\
\text { Squares }\end{array}$ & df & $\begin{array}{c}\text { Mean } \\
\text { Square }\end{array}$ & $\mathbf{F}$ & Sig. \\
\hline \multirow{5}{*}{$\begin{array}{l}\text { Acceleration } \\
\text { for } \\
\text { Accelerating }\end{array}$} & Between & 1.144 & 2 & \multirow[t]{5}{*}{.572} & \multirow[t]{5}{*}{4.680} & \multirow[t]{5}{*}{.009} \\
\hline & Groups & & & & & \\
\hline & Within & 22696.969 & 185680 & & & \\
\hline & Groups & & & & & \\
\hline & Total & 22698.114 & 185682 & & & \\
\hline \multirow{5}{*}{$\begin{array}{l}\text { Acceleration } \\
\text { for Braking }\end{array}$} & Between & 33.316 & 2 & \multirow[t]{5}{*}{16.658} & \multirow[t]{5}{*}{56.833} & \multirow[t]{5}{*}{.000} \\
\hline & Groups & & & & & \\
\hline & Within & 53347.408 & 182009 & & & \\
\hline & Groups & & & & & \\
\hline & Total & 53380.724 & 182011 & & & \\
\hline \multirow{4}{*}{ Speed } & Between & 467137.180 & 2 & 233568.590 & \multirow[t]{4}{*}{343.122} & \multirow[t]{4}{*}{.000} \\
\hline & $\begin{array}{l}\text { Groups } \\
\text { Within }\end{array}$ & 339293850.589 & 498437 & 680.716 & & \\
\hline & Groups & & & & & \\
\hline & Total & 339760987.769 & 498439 & & & \\
\hline
\end{tabular}

Table 3. Mean and maximum speed and acceleration control at different working shift hour

\begin{tabular}{|l|r|r|r|c|c|c|c|}
\hline & \multicolumn{2}{|c|}{ Accelerating } & \multicolumn{2}{c|}{ Braking } & \multicolumn{3}{|c|}{ Speed (km/h) } \\
\cline { 2 - 7 } & Mean & \multicolumn{1}{|c|}{ Max } & Mean & Max & Mean & \multicolumn{1}{c|}{ Max } & \multicolumn{1}{c|}{ Min } \\
\hline Morning & .337 & 2.167 & -.550 & -4.403 & 29.481 & 86.50 & .000 \\
$(6.00 \mathrm{am}-3.00 \mathrm{pm})$ & & & & & & 0 & \\
$\begin{array}{l}\text { Afterrnoon } \\
(3.00 \mathrm{pm}-12.00 \mathrm{am})\end{array}$ & .333 & 2.694 & -.516 & -5.375 & 26.934 & 86.70 & .000 \\
$\begin{array}{l}\text { Direct } \\
(6.00 \mathrm{am}-12.00 \mathrm{am})\end{array}$ & .339 & 2.389 & -.541 & -3.875 & 27.969 & $\begin{array}{r}87.90 \\
0\end{array}$ & .000 \\
\hline
\end{tabular}

Table 4. Mean of acceleration and speed of the driver who work for direct shift

\begin{tabular}{|l|r|r|r|}
\hline \multirow{2}{*}{} & \multicolumn{3}{|c|}{ Driving control } \\
\cline { 2 - 4 } & Accelerating & Braking & Speed $(\mathrm{km} / \mathrm{h})$ \\
\hline Morning & .3453 & -.5586 & 28.1690 \\
\hline Afternoon & .3310 & -.5162 & 27.6995 \\
\hline
\end{tabular}

Fig. 8 shows how drivers dealtwith acceleration at specific speed range while accelerating and braking. The figure shows that at speed lower than $30 \mathrm{~km} / \mathrm{h}$, the $85^{\text {th }}$ percentile acceleration of drivers who work in the morning shift were found to be sharper than the afternoon shift. At higher speed, drivers accelerating and braking behavior were considerably similar for all working shift hour.

\subsection{Impact of bus driving variation on fuel consumption}

The variations of speed and acceleration control of bus driving in the city areas contributed to disparity of bus fuel usage. As presented in Fig. 2 and Fig. 3, majority of bus fuel were used for accelerating. The accelerating behavior consumed $72 \%$ of the total bus fuel usage for all working shift hour. Besides, although drivers spent almost equal duration for braking and accelerating, the analysis conducted suggested that only $19 \%$ of fuel usage is used for 
braking (Table 5). Overall result also shows that, lesser fuel is consumed for cruising and idling.

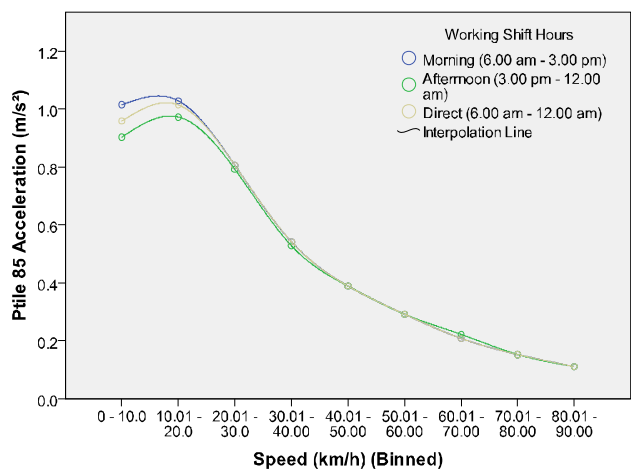

(a) Accelerating

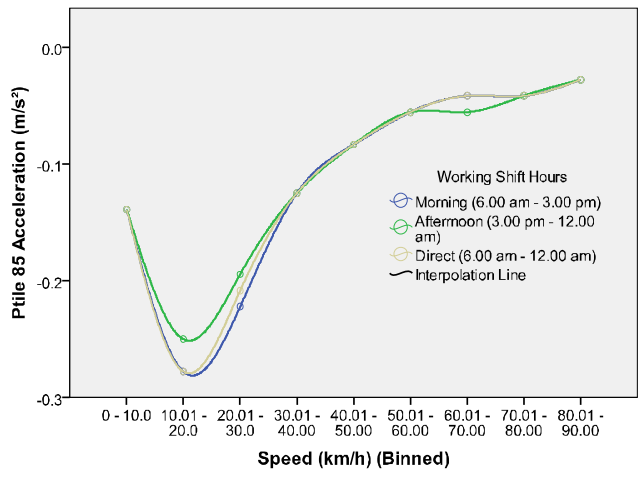

(b) Braking

Fig. 8. Comparison of acceleration applied by drivers at specific speed range during accelerating and braking

Table 5. Proportion of bus fuel consumption based on different driving phase and Working shift hour

\begin{tabular}{|c|c|c|c|c|}
\hline & Accelerating & Braking & Cruising & Idling \\
\hline $\begin{array}{l}\text { Morning }(6.00 \mathrm{am}- \\
3.00 \mathrm{pm}) \\
\text { Afterrnoon }(3.00 \mathrm{pm}- \\
12.00 \mathrm{am}) \\
\text { Direct }(6.00 \mathrm{am}-12.00 \\
\text { am) }\end{array}$ & $\begin{array}{l}72 \% \\
72 \% \\
72 \% \\
\end{array}$ & $\begin{array}{l}19 \% \\
18 \% \\
19 \% \\
\end{array}$ & $\begin{array}{l}4 \% \\
4 \% \\
4 \% \\
\end{array}$ & $\begin{array}{l}5 \% \\
6 \% \\
6 \% \\
\end{array}$ \\
\hline
\end{tabular}

This study evaluates the correlation between speed, acceleration and fuel consumption. Non-linear relationship was investigated. Table 6 shows the correlation coefficients. As presented, positive and good correlation can be seen between speed, acceleration and fuel consumption. A scatterplot demonstrated in Fig. 9 summarises the results.

Table 6. Correlation test between speed, acceleration and fuel consumption

\begin{tabular}{|ll|r|r|r|}
\hline & \multicolumn{1}{|c|}{$\begin{array}{c}\text { Acceleration } \\
\left(\mathbf{m} / \mathbf{s}^{\mathbf{2}}\right)\end{array}$} & \multicolumn{1}{c|}{$\begin{array}{c}\text { Inst. Fuel } \\
(\mathbf{m L})\end{array}$} & \multicolumn{1}{c|}{$\begin{array}{c}\text { Speed } \\
(\mathbf{k m} / \mathbf{h})\end{array}$} \\
\hline $\begin{array}{l}\text { Acceleration } \\
\left(\mathrm{m} / \mathrm{s}^{2}\right)\end{array}$ & Correlation & 1 & .539 & -.072 \\
& Sig. (2-tailed) & & .000 & .000 \\
& $\mathrm{~N}$ & 498441 & 498441 & 498441 \\
\hline $\begin{array}{l}\text { Inst. Fuel } \\
(\mathrm{mL})\end{array}$ & Correlation & .539 & 1 & .477 \\
& Sig. (2-tailed) & .000 & & .000 \\
& $\mathrm{~N}$ & 498441 & 498441 & 498441 \\
\hline Speed $(\mathrm{km} / \mathrm{h})$ & Correlation & -.072 & .477 & 1 \\
& Sig. (2-tailed) & .000 & .000 & \\
& $\mathrm{~N}$ & 498441 & 498441 & 498441 \\
\hline
\end{tabular}




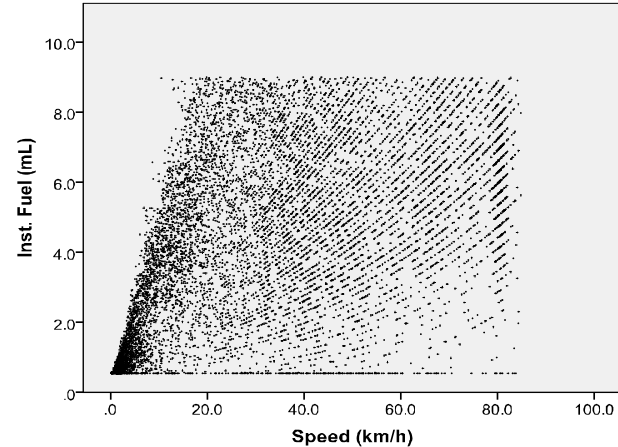

(a)

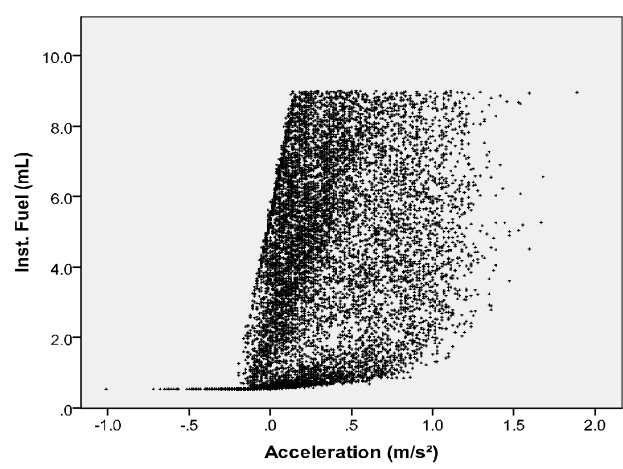

(b)

Fig. 9. Relationship between (a) speed and Instantaneous fuel consumption and (b) acceleration and instantaneous fuel consumption

Further investigation on bus fuel consumption has been conducted to compare the differences of fuel used between morning and afternoon shifts. The result presented in Table 7 and Table 8 shows that, the drivers who drove during morning shift consumed 4\% significantly higher fuel than drivers who drove during afternoon shift. This expected result, is consistent with drivers' negotiation on speed and acceleration as presented previously in this paper which showed, morning shift driversapplied higher speed and sharper acceleration rate.

Specifically, Fig. 10 presents the mean of instantaneous fuel consumption at every $10 \mathrm{~km} / \mathrm{h}$ speed bin. Overall data exhibit that fuel consumption increases as speed increases. In addition, it can be highlighted that, sharp increase in fuel consumption occurred at speed range $0-20 \mathrm{~km} / \mathrm{h}$. However, within the $20.01 \mathrm{~km} / \mathrm{h}$ to $50 \mathrm{~km} / \mathrm{h}$ speed range, the fuel consumption is likely to remain steady. The figure also shows that, within the speed range of $50.01 \mathrm{~km} / \mathrm{h}$ to $80 \mathrm{~km} / \mathrm{h}$, the fuel increased approximately linearly with the increase in speed.

Table 7. Comparison of bus fuel consumption between morning and afternoon shift hour

\begin{tabular}{|l|r|}
\hline $\mathrm{t}$ & 14.232 \\
$\mathrm{df}$ & 498390.384 \\
Sig. (2-tailed) & .000 \\
Mean Difference & .0981 \\
Std. Error Difference & .0069 \\
\cline { 1 - 1 } 95\% Confidence & Lower \\
\cline { 2 - 2 } $\begin{array}{l}\text { Interval of the } \\
\text { Difference }\end{array}$ & .0846 \\
\hline
\end{tabular}


Table 8. Descriptive analysis of bus fuel consumption for morning and afternoon shift hour

\begin{tabular}{|l|r|r|r|r|}
\hline Working shift hour & $\mathrm{N}$ & \multicolumn{1}{|c|}{$\begin{array}{c}\text { Mean of fuel } \\
\text { consumption } \\
(\mathrm{ml} / \mathrm{s})\end{array}$} & $\begin{array}{c}\text { Std. } \\
\text { Deviation }\end{array}$ & $\begin{array}{c}\text { Std. } \\
\text { Error } \\
\text { Mean }\end{array}$ \\
\hline Morning $(6.00 \mathrm{am}-3.00 \mathrm{pm})$ & 254034 & 2.3279 & 2.4700 & .00 \\
Afterrnoon $(3.00 \mathrm{pm}-12.00 \mathrm{am})$ & 244406 & 2.2298 & 2.3997 & .00 \\
\hline
\end{tabular}

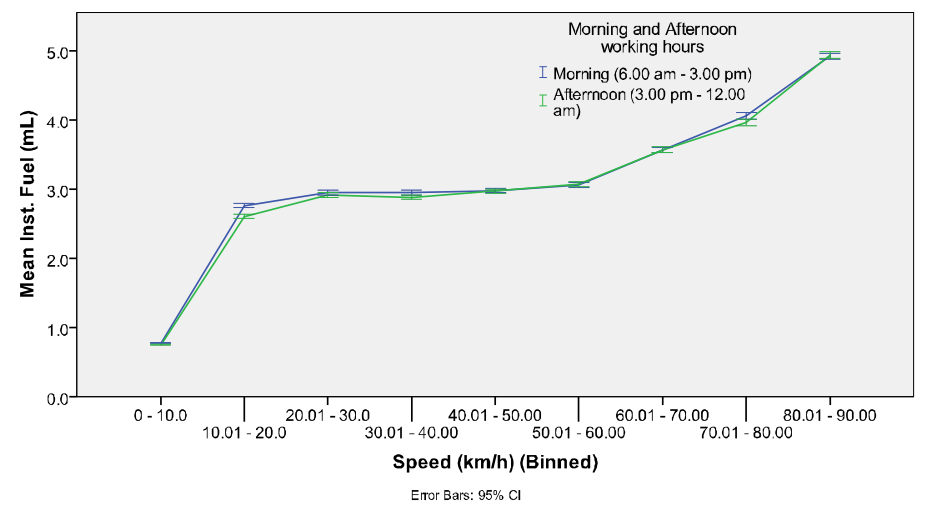

Fig. 10. Mean of instantaneous fuel consumption vs. Speed

Table 9. Mean of acceleration at different speed range

\begin{tabular}{|c|c|c|c|c|}
\cline { 2 - 5 } \multicolumn{1}{c|}{} & \multicolumn{2}{c|}{ Accelerating } & \multicolumn{2}{c|}{ Braking } \\
\hline Speed range & $\begin{array}{c}\text { Morning } \\
\text { shift }\end{array}$ & $\begin{array}{c}\text { Afternoon } \\
\text { shift }\end{array}$ & $\begin{array}{c}\text { Morning } \\
\text { shift }\end{array}$ & $\begin{array}{c}\text { Afternoon } \\
\text { shift }\end{array}$ \\
\hline $0-20 \mathrm{~km} / \mathrm{h}$ & .5673 & .5161 & -.6944 & -.7487 \\
\hline $20.01-50 \mathrm{~km} / \mathrm{h}$ & .3410 & .3323 & -.5163 & -.5537 \\
\hline $50.01-90 \mathrm{~km} / \mathrm{h}$ & .0889 & .0828 & -.2471 & -.2635 \\
\hline
\end{tabular}

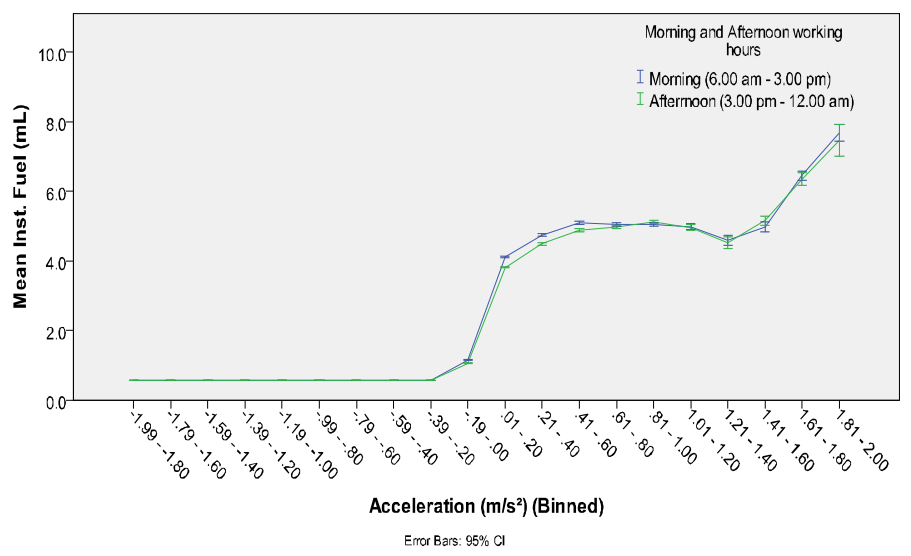

Fig. 11. Mean of instantaneous fuel consumption vs. acceleration 
The analysis on acceleration impact on fuel consumption is also assessed in this study. Fig. 11 shows that the bus fuel consumption rate increased as the acceleration increases when drivers increased the acceleration rate $\left(>0 \mathrm{~ms}^{-2}\right)$. While as drivers reduce the speed (decelerating), minimum fuel is consumed.

\section{Conclusion}

The results from this study found that there are differences in bus driving behavior and working shift. The bus drivers used high speed and high acceleration in the morning shift. The drivers also used sharp braking in the morning shift compared to afternoon shift. This is related to the busy traffic condition in the morning as everyone isrushing to the workplace. This condition also impacts fuel consumption. This study indicates that for all driving shifts, the bus drivers were found to consume more than $70 \%$ fuel while accelerating and braking.

As a conclusion, working shift has an influence on bus driving behavior and fuel consumption. Therefore, bus companies should take action with these issues. Further study should be carried out with express buses.

We are grateful to Siti Maisarah Che Hasan, Universiti Tun Hussein Onn Malaysia for her contribution to this study and the Ministry of Higher Education, Malaysia for funding and supporting this research project under grant code FRGS 1451

\section{References}

[1] Rospa, Driver Fatigue and Road Accidents, The Royal Society for the Prevention of Accidents, (2001)

[2] J. Horne, L. Reyner, Vehicle accidents related to sleep: A review, Occupational and Environmental Medicine, 56(5), 289-94 (1999)

[3] H.D. Howarth, An Investigation of Sleep And Fatigue In Transit Bus Operators on Different Work Schedules, (2002)

[4] T. Sando, E. Mtoi, R. Moses, Potential Causes of Driver Fatigue : A Study on Transit Bus Operators In Florida, (2010)

[5] A.D.N.M. Abdullah, H. L. Von, Factors of fatigue and bus accident, International Conference on Innovativation, Management and Service, (2011)

[6] M.M. Rohani, Bus Driving Behaviour and Fuel Consumption, $\mathrm{PhD}$ Thesis, University of Southampton, (2012)

[7] J. Van Mierlo, G. Maggetto, E. Van De Burgwal, R. Gense, Driving style and traffic measures-influence on vehicle emissions and fuel consumption, Journal of Automobile Engineering, 218(1), 43-50 (2004)

[8] I. De Vlieger, D. De Keukeleere, J.G. Kretzschmar, Environmental effects of driving behaviour and congestion related to passenger cars, Atmos. Environ., 34(27), 46494655, (2000)

[9] B. Beusen, S. Broekx, T. Denys, C. Beckx, B. Degraeuwe, M. Gijsbers, L.L. Panis, Using on-board logging devices to study the long-term impact of an eco-driving course, Transportation Research - Part D, 14, 514-520 (2009) 